\title{
Relation between potential and catalytic activity of rhodium in propylene combustion
}

\author{
G. FÓTI*, I. BOLZONELLA, D. BACHELIN and CH. COMNINELLIS \\ Institute of Chemical and Biological Process Science, School of Basic Sciences, Swiss Federal Institute of Technology, \\ CH-1015 Lausanne, Switzerland \\ (*author for correspondence, e-mail: gyorgy.foti@epfl.ch)
}

Received 28 February 2003; accepted in revised form 13 June 2003

Key words: catalyst potential, electrochemical promotion, ethylene combustion, rhodium

\begin{abstract}
The relation between the catalyst potential and the catalytic performance has been investigated in the gas-phase combustion of propylene with oxygen over rhodium catalysts at $375^{\circ} \mathrm{C}$. The rhodium catalyst, deposited on yttriastabilized zirconia (YSZ) solid electrolyte, also served as working electrode in the electrochemical cell. Under opencircuit conditions, the measured catalyst potential was found to be a sensitive indicator of the oxidation state of the rhodium catalyst, which influences the catalytic reaction rate dramatically and depends strongly both on the method of catalyst film preparation and on the composition of the reacting gas mixture. In turn, under closed-circuit conditions, the applied catalyst potential is a convenient tool to maintain the catalyst in its more active, reduced form and to control its catalytic performance. The activity of atomic oxygen at the three-phase boundary (tpb) during open-circuit catalytic reaction was estimated from solid electrolyte potentiometric (SEP) measurements, in good agreement with the average surface oxidation state obtained from XRD and XPS analyses. O/Rh atomic ratios higher than stoichiometric were found by XPS at the outer surface of the catalysts suggesting a strong open circuit $\mathrm{O}^{2-}$ spillover due to strong metal support interactions (SMSI) and a concomitant extension of the electric double layer to the gas-exposed catalyst surface, similarly to emersed electrodes in aqueous electrochemistry. Applying potentials up to several hundreds of $\mathrm{mV}$, highly nonfaradaic promotion of propylene combustion was achieved. Electrochemical promotion of catalysis (EPOC) was most efficient at stoichiometric gas composition, that is, close to the limit of surface reduction, and with the catalyst exhibiting the smallest $\mathrm{O}^{2-}$ spillover population at open-circuit conditions.
\end{abstract}

\section{Introduction}

Rhodium is a promising candidate for use as a catalyst in several gas-phase reactions of strong environmental impact, such as the combustion of unsaturated hydrocarbons and the selective reduction of NOx pollutants. However, despite its high activity and selectivity, a rhodium catalyst is difficult to employ because the mechanism may suddenly change depending on the reacting gas composition [1]. The reason for this is that, unlike other noble metals of group VIII, rhodium easily forms surface oxides, and its oxidation state strongly influences its catalytic activity [2]. In a net oxidizing environment, the surface of a rhodium catalyst is composed mainly of $\mathrm{Rh}_{2} \mathrm{O}_{3}$, whereas treatment with net reducing stream yields predominantly metallic rhodium at the surface [2, 3]. Adsorption studies on rhodium catalyst have shown that oxygen adsorbs very easily on metallic rhodium, and it can be readily removed from the surface by a reducing gas [4]. The change in the oxidation state is fully reversible between 200 and $500{ }^{\circ} \mathrm{C}$, whereas at higher temperature oxidiz- ing conditions may cause irreversible deactivation of the catalyst [5]. As a general rule, reduced (metallic) rhodium exhibits much higher catalytic activity than rhodium oxide [2].

The oxidation state of the rhodium catalyst is closely related to its potential. The latter can be suitably measured in an electrochemical cell where the catalyst film (working electrode), and also the catalytically inert counter and reference electrodes usually made of gold, are deposited on a solid electrolyte. In this work, yttriastabilized zirconia (YSZ), an $\mathrm{O}^{2-}$ ion conducting material at the temperature of catalytic rate measurements $\left(375^{\circ} \mathrm{C}\right)$, will be used as solid electrolyte support. This electrochemical cell configuration allows not only the measurement of the open-circuit catalyst potential with respect to that of the reference electrode in a solid electrolyte potentiometric (SEP) experiment [6-8], but also the application of a potential (or current) to the catalyst. In this closed-circuit operation, the applied potential or current is an independent variable used to tune the activity and/or the selectivity of the catalyst, which results in a marked, and very often highly 
nonfaradaic, change in the catalytic reaction rate. This recently discovered phenomenon [9], called electrochemical promotion of catalysis (EPOC) or nonfaradaic electrochemical modification of catalytic activity (NEMCA effect) [10-12], has made a strong impact on modern electrochemistry [13, 14], catalysis [15] and surface science $[16,17]$. EPOC is a general phenomenon in heterogeneous catalysis, verified for over seventy different catalytic reactions over a wide range of metal but also metal oxide ( $\mathrm{IrO}_{2}$ [18-20] and $\mathrm{RuO}_{2}$ [21-25]) catalysts. Obviously, the catalyst potential plays a key role in the control of catalytic activity by EPOC.

Rhodium catalysts are commonly prepared by thermal decomposition of suitable precursors, such as rhodium chloride [26-31], rhodium nitrate [32, 33], or commercial organo-rhodium pastes [34]. The method consists of wet impregnation of the support with a solution of the precursor, followed by drying, firing and chemical reduction. Another technique frequently used to deposit thin films is metal sputtering, induced by bombardment of a target (rhodium) with high-energy atomic particles (e.g., argon). The key parameters of the sputtering procedure are the pressure and the ion beam energy [35]. In the present work, two types of rhodium catalysts were prepared by thermal decomposition of rhodium chloride precursor at two different temperatures, and compared with a third catalyst prepared by rhodium sputtering in argon atmosphere. In addition to evident morphological differences, the thermally deposited films are presumably composed of oxidized rhodium compounds, whereas the sputtered catalyst coating is expected to contain metallic rhodium in its bulk.

Using rhodium catalysts, kinetic studies coupled with catalyst potential measurements under electrochemical promotion conditions were reported for the combustion of ethylene [34, 36, 37]. The reaction exhibited electrophobic behaviour, meaning increasing reaction rate when applying positive potential, and the achieved enhancement was among the highest obtained so far during EPOC experiments, explained with the strong dependence of the reaction rate on the oxidation state of the catalyst. EPOC-assisted reduction of the rhodium surface was reported also in connection with the reduction of NO with propylene [38] where the promotion was found irreversible at low temperature $\left(300{ }^{\circ} \mathrm{C}\right)$. It has been stated that, in analogy with strong metalsupport interactions [39], electrochemical promotion is due to oxygen back-spillover generated electrochemically at the three-phase boundary. This causes weakening of the chemisorptive bond strength of electron acceptor adsorbates (e.g., oxygen) making easier the reduction of surface oxides to metallic rhodium [34, 36, 37]. In the present work, the relation between catalyst potential and catalytic performance will be studied under both opencircuit and closed-circuit conditions. The combustion of propylene with oxygen at $375^{\circ} \mathrm{C}$ over differently prepared rhodium catalysts will be taken as a model reaction.

\section{Experimental details}

The electrochemical cells were of the single-pellet type shown in Figure 1. The solid electrolyte supports, YSZ pellets $\left(\mathrm{ZrO}_{2}-\mathrm{FSZ}\right.$, Dynamic Ceramic Ltd) of $1 \mathrm{~mm}$ thickness, were sandblasted before electrode deposition. The working electrode (rhodium catalyst) and the gold counter electrode had a geometrical surface area of $0.5 \mathrm{~cm}^{2}$ and were deposited in a symmetrical face-toface arrangement onto the opposite sides of the solid electrolyte pellet, while the small-sized gold reference electrode was deposited next to the counter electrode at a minimum distance of $2 \mathrm{~mm}$. This geometry ensured a symmetrical current and potential distribution in the cell [40]. The gold counter and reference electrodes were deposited onto the YSZ support by thermal decomposition of a low-temperature commercial gold paste (C1991025R2, Gwent Electronic Materials Ltd) at $550{ }^{\circ} \mathrm{C}$. The catalyst films (working electrode) were deposited by two different techniques: rhodium sputtering, and thermal decomposition of $\mathrm{RhCl}_{3}$ precursor.

Rhodium deposition by sputtering onto YSZ was preceded by a series of subsequent steps of surface cleaning: immersion in a commercial solution of $5 \%$ Contrad 90 (Decon Laboratories Ltd) in water for $12 \mathrm{~h}$, treatment in an ultrasonic bath for $5 \mathrm{~min}$, rinsing for 2 min with demineralized water, immersion in 2-propanol, treatment for $5 \mathrm{~min}$ in ultrasonic bath, and drying with a nitrogen stream. In the sputtering chamber, containing high-purity Ar (99.9999\%, Carbagas) at a pressure of $0.5 \mathrm{~Pa}$, the YSZ support was first cleaned with argon ion bombardment, then rhodium was sputtered onto the substrate at $400{ }^{\circ} \mathrm{C}$ by cathodic pulverization of a target (Rh 99.9\%, Engelhard). The process was performed in radio-frequency $(\mathrm{RF})$ mode of plasma generation with a working power of $100 \mathrm{~W}$ on

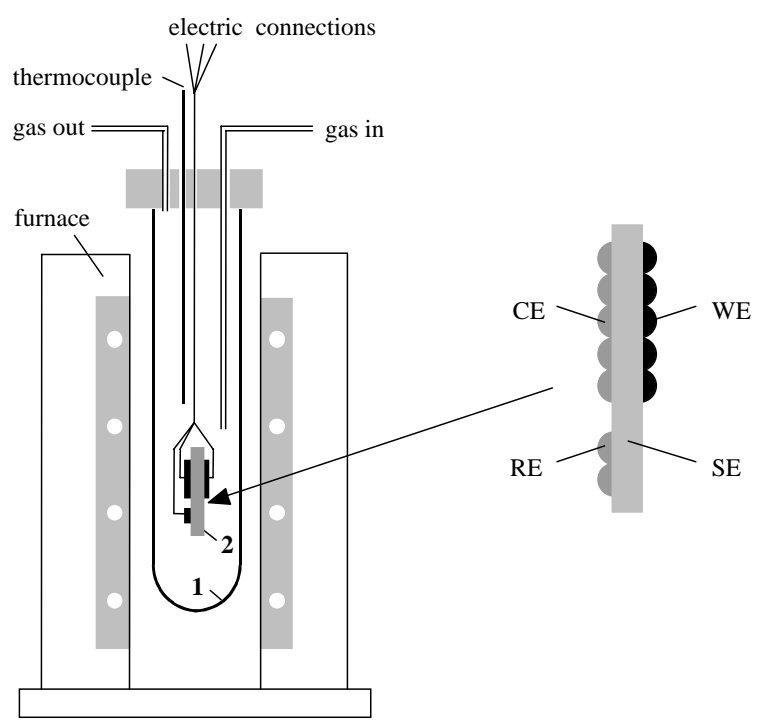

Fig. 1. Reactor assembly and furnace used with the single-pellet configuration. Keys: (1) glass tube; volume $88 \mathrm{ml}$, (2) electrochemical cell; (WE) working electrode (catalyst); (CE) gold counter electrode; (RE) gold reference electrode; (SE) solid electrolyte (YSZ). 
the target. Under these conditions the deposition rate was $0.5 \mathrm{~nm} \mathrm{~s}^{-1}$. The thickness of the produced rhodium film, estimated through calibration on simultaneously processed smooth silicon samples, was $0.2 \mu \mathrm{m}$. Throughout this paper this sample will be denoted $\mathbf{S p}$.

By thermal decomposition, two different rhodium catalyst films were prepared by the same procedure, except for the decomposition temperature of the rhodium chloride precursor salt. Previous thermogravimetric analysis (TGA) showed that during thermal decomposition of the precursor in air anhydrous $\mathrm{RhCl}_{3}$ and $\mathrm{Rh}_{2} \mathrm{O}_{3}$ were formed above 400 and $700{ }^{\circ} \mathrm{C}$, respectively. Accordingly, the two different temperatures chosen for the thermal decomposition were 500 and $800{ }^{\circ} \mathrm{C}$. Throughout this paper these samples will be denoted $\mathbf{T d}_{500}$ and $\mathbf{T d}_{800}$, respectively. The precursor salt, $\mathrm{RhCl}_{3} \cdot 2 \mathrm{H}_{2} \mathrm{O}$ (Alfa, 011032), was dissolved in 1:1 (volume) water:2-propanol (Fluka, 59309) solution with a metal content of $0.1 \mathrm{M}$. With a micropipette $3 \mu \mathrm{l}$ of the precursor solution were applied onto the YSZ support, the solvent was evaporated at $100{ }^{\circ} \mathrm{C}$ for $5 \mathrm{~min}$, then the sample was gradually heated up to the chosen decomposition temperature (either 500 or $800{ }^{\circ} \mathrm{C}$ ), and kept at this temperature for $10 \mathrm{~min}$. After the deposition of four subsequent layers (estimated film thickness $0.2 \mu \mathrm{m}$ ) the sample was heated for $1 \mathrm{~h}$ at the temperature of the decomposition treatment.

X-ray diffraction (XRD) measurements were carried out with a diffractometer (D500, Siemens) at values of $2 \theta$ between 5 and $95^{\circ}$ using $\mathrm{Cu} K_{\alpha}$ radiation. The angle was varied with a step size of $0.04^{\circ}$ and a step time of $4 \mathrm{~s}$. SEM micrographs were taken with a scanning electron microscope (JSM-6300F, Jeol). X-ray photoelectron spectroscopy (XPS) was performed with a spectrometer (PHI 5500 ESCA, Perkin-Elmer) in the energy range between 0 and $1100 \mathrm{eV}$ using the $K_{\alpha}$ radiation of $\mathrm{Mg}$. XRD, SEM and XPS analyses were performed with the catalysts as prepared and also after oxidation of the $\mathrm{Sp}$ sample with $20 \%$ of $\mathrm{O}_{2}$ in helium as well as reduction of the $\mathbf{T d}$ samples with $0.5 \%$ of propylene in helium, both treatments made at $375^{\circ} \mathrm{C}$ for $12 \mathrm{~h}$.

The one-chamber reactor for kinetic measurements is shown in Figure 1. It consisted of a glass tube $(V=$ $88 \mathrm{ml}$ ), closed with a stainless steel cap and operated at atmospheric pressure. Earlier studies under similar flow conditions showed a CSTR (continuous stirred tank reactor) behaviour [42] meaning that the gas composition in the reactor was uniform and identical to that measured at the outlet. The electrochemical cell was suspended inside the reactor with three gold wires (dia. $0.15 \mathrm{~mm}$, Cendres \& Métaux SA), serving also as electric contacts to the electrodes. The temperature in the reactor was measured with a $\mathrm{K}$-type $(\mathrm{NiCr}-\mathrm{Ni})$ thermocouple placed close to the catalyst surface. The reactor was placed in a furnace (XVA271, Horst) equipped with a heat control system (HT30, Horst). Reactants were Carbagas certified standards of $\mathrm{C}_{3} \mathrm{H}_{6}$ $(99.4 \%)$ and $\mathrm{O}_{2}(99.95 \%)$, supplied as $1 \%\left(\mathrm{C}_{3} \mathrm{H}_{6}\right)$ or
$20 \%\left(\mathrm{O}_{2}\right)$ mixtures in $\mathrm{He}(99.996 \%)$. The balance was helium. The gas flow was controlled by mass control systems (F/201C and E-5514-FA, Bronkhorst). $\mathrm{C}_{3} \mathrm{H}_{6}$, $\mathrm{CO}_{2}$ and $\mathrm{CO}$ were monitored with online infrared (NDIR) analysers (Ultramat 5E-2R; Siemens). Analysis of $\mathrm{O}_{2}$ was made with an offline gas chromatograph (GC8A, Shimadzu, detector TCD, column Alltech 5S CTR packed with Chromosorb 107 and molecular sieve 5A). Closed-circuit experiments were made in galvanostatic mode with a scanning galvano-potentiostat (Princeton Applied Research, model 362, EG\&G). The catalyst potential measured in the given system may have a systematic experimental error for two reasons. On one hand, in the single-chamber reactor the gold reference electrode was exposed to varying gas composition hence its potential might change and, on the other hand, gold is not a perfect reference electrode material under the given experimental conditions because the redox couple, which defines its potential, is not ideally reversible [41]. The resultant error of the catalyst potential was estimated to be less than $20 \mathrm{mV}$ under typical EPOC conditions, where the applied current does usually not exceed $100 \mu \mathrm{A}$.

Reactive surface titration of the catalysts [10] was performed at $375^{\circ} \mathrm{C}$ in the same reactor, which was used for the kinetic measurements. First the catalyst was reduced with $0.5 \%$ of propylene in helium for $20 \mathrm{~min}$ then the reducing gas mixture present in the reactor was purged out with pure helium. After the purge period, the reactor was immediately flowed with $2 \%$ of oxygen in helium, and $\mathrm{CO}_{2}$ at the outlet was monitored, which was the only product of the reaction between oxygen and adsorbed propylene (see later). Due to the desorption of propylene during the purge with helium, the $\mathrm{CO}_{2}$ production decreased with increasing purging time, which was varied between 2 and $7 \mathrm{~min}$. The maximum propylene uptake before purging the system was obtained by extrapolation of the produced $\mathrm{CO}_{2}$ to zero purging time.

\section{Results and discussion}

The main morphological, structural and chemical characteristics of the $\mathbf{S p}, \mathbf{T d}_{500}$ and $\mathbf{T} \mathbf{d}_{800}$ rhodium catalyst films obtained by XRD, SEM and XPS analyses are summarized in Table 1. XRD showed different morphology and different chemical composition of the catalyst films depending on the method of preparation. The Sp catalyst was found crystalline, and its chemical composition was pure metallic rhodium, consequent to its deposition in inert atmosphere. The $\mathbf{T} \mathbf{d}_{500}$ catalyst was found completely amorphous, hence inactive in XRD, while the $\mathbf{T d}_{800}$ catalyst showed a definite crystalline structure of rhodium oxide $\left(\mathrm{Rh}_{2} \mathrm{O}_{3}\right)$. As it was already foreseen from previous TGA experiments, higher calcination temperature is favourable to the formation of rhodium oxide. When oxidizing the Sp catalyst film with oxygen, or when reducing the $\mathbf{T} \mathbf{d}_{500}$ 
Table 1. Morphological and chemical structure of the $\mathbf{S p}, \mathbf{T d}_{500}$ and $\mathbf{T} \mathbf{d}_{800}$ rhodium catalyst films deposited on YSZ solid electrolyte support Oxidation of the Sp sample was made with $20 \%$ of $\mathrm{O}_{2}$ in helium at $375^{\circ} \mathrm{C}$ for $12 \mathrm{~h}$.

Reduction of the $\mathbf{T} \mathbf{d}_{500}$ and $\mathbf{T} \mathbf{d}_{800}$ samples was performed with $0.5 \%$ of propylene in $\mathrm{He}$ at $375{ }^{\circ} \mathrm{C}$ for $12 \mathrm{~h}$.

Measurements at a depth of $5 \mathrm{~nm}$ were made after erasing the surface by argon sputtering.

\begin{tabular}{lllll}
\hline Analysis & Description & Sp & $\mathbf{T d}_{500}$ & $\mathbf{T d}_{800}$ \\
\hline XRD & $\begin{array}{l}\text { Morphology and chemical } \\
\text { composition of the bulk of } \\
\text { the catalyst film }\end{array}$ & $\begin{array}{l}\text { Crystalline (Rh) as } \\
\text { prepared } \\
\text { Remains reduced after } \\
\text { oxidation }\end{array}$ & Amorphous & $\begin{array}{l}\text { Crystalline }\left(\mathrm{Rh}_{2} \mathrm{O}_{3}\right) \text { as } \\
\text { prepared } \\
\text { Remains oxidized after } \\
\text { reduction }\end{array}$ \\
SEM & $\begin{array}{l}\text { Structure of the surface } \\
\text { of the catalyst film }\end{array}$ & $\begin{array}{l}\text { Uniform grains } \\
\text { Hardly influenced by } \\
\text { oxidation }\end{array}$ & $\begin{array}{l}\text { Large cracks } \\
\text { Disappear after reduction }\end{array}$ & $\begin{array}{l}\text { Scarcely cracked } \\
\text { Hardly influenced by } \\
\text { reduction }\end{array}$ \\
XPS & $\begin{array}{l}\text { Chemical composition of the } \\
\text { outer surface }\end{array}$ & $\begin{array}{l}\text { Metallic as prepared } \\
\text { Remains partially reduced } \\
\text { after oxidation }\end{array}$ & $\begin{array}{l}\text { Poorly defined as prepared } \\
\text { Becomes metallic after } \\
\text { reduction }\end{array}$ & $\begin{array}{l}\text { Oxidized }\left(\mathrm{Rh}_{2} \mathrm{O}_{3}\right) \text { as prepared } \\
\text { Becomes metallic after } \\
\text { reduction }\end{array}$ \\
XPS & $\begin{array}{l}\text { Chemical composition of the } \\
\text { catalyst film at } 5 \mathrm{~nm} \text { depth }\end{array}$ & $\begin{array}{l}\text { Remains reduced after } \\
\text { oxidation }\end{array}$ & $\begin{array}{l}\text { Remains ill-defined after } \\
\text { reduction }\end{array}$ & $\begin{array}{l}\text { Remains oxidized after } \\
\text { reduction }\end{array}$ \\
\hline
\end{tabular}

and $\mathbf{T d}_{800}$ catalysts with propylene, no significant alterations on their XRD pattern were observed. The expected changes in the rhodium oxidation state were apparently localized at the surface of the catalyst films, and XRD is not appropriate to monitor surface properties.

SEM of the samples, as prepared, showed quite different patterns. The Sp rhodium showed a homogeneous film with no cracks or discontinuities, and the film comprised fairly uniform small grains of less than $100 \mathrm{~nm}$ size. The $\mathbf{T d}_{500}$ sample exhibited large surface cracks, which is typical of metal oxide structures [21, 42], while the $\mathbf{T d}_{800}$ film showed only a few small cracks. Apparently, higher preparation temperature results in a decrease in the size and number of cracks, a phenomenon similar to sintering. Oxidizing or reducing treatment resulted in significant surface modification only in the case of the $\mathbf{T} \mathbf{d}_{500}$ catalyst, causing the majority of the cracks to disappear.

XPS in the binding energy range of the $3 d_{5 / 2}$ electron of rhodium showed that the $\mathbf{S p}$ catalyst, as prepared, was composed of metallic rhodium, and the oxidizing treatment caused only partial oxidation. In the $\mathbf{T} \mathbf{d}_{500}$ and $\mathbf{T} \mathbf{d}_{800}$ catalysts, as prepared, rhodium in high oxidation state was found, although in the $\mathbf{T} \mathbf{d}_{500}$ sample the composition was not well defined and also some residual chlorine (less than $2 \%$ ) was detected indicating incomplete decomposition of the $\mathrm{RhCl}_{3}$ precursor during calcination at $500{ }^{\circ} \mathrm{C}$. The reducing treatment of both Td catalysts resulted in a net shift of the electron binding energy toward that of metallic rhodium and also a complete elimination of chlorine from the surface of the $\mathbf{T} \mathbf{d}_{500}$ sample. Table 2 shows the $\mathrm{O} / \mathrm{Rh}$ atomic ratios found by XPS. The relative atomic abundances measured at a depth of $5 \mathrm{~nm}$ (after erasing the surface by argon ion bombardment) were in reasonably good agreement with the expected chemical composition of the samples: $\mathbf{S p}$ being metallic, $\mathbf{T d}_{500}$ not fully decomposed, $\mathbf{T} \mathbf{d}_{800}$ mainly an oxide. At the outer surface of the samples, however, oxygen contents significantly higher
Table 2. XPS analysis of atomic abundances in terms of $\mathrm{O} / \mathrm{Rh}$ ratio at Sp, $\mathbf{T d}_{500}$ and $\mathbf{T d}_{800}$ rhodium catalyst films deposited on YSZ solid electrolyte support*

\begin{tabular}{llll}
\hline Analysis & \multicolumn{3}{l}{ Atomic ratio $\mathrm{O} / \mathrm{Rh}$} \\
\cline { 2 - 4 } & $\mathbf{S p}$ & $\mathbf{T d}_{500}$ & $\mathbf{T d}_{800}$ \\
\hline As prepared & 0.82 & 2.69 & 2.62 \\
After oxidation & 0.50 & - & - \\
After reduction & - & 2.86 & 2.88 \\
At 5 nm depth & 0.08 & 0.92 & 1.29 \\
\hline
\end{tabular}

* Oxidation and reduction procedure as in Table 1.

than stoichiometric were found. The effect was particularly pronounced with the thermally prepared catalysts, and in all cases the reduced surfaces exhibited higher oxygen content. The excess surface oxygen may be partly attributed to oxygen adsorption, but it may also indicate that the catalysts, especially the thermally prepared samples, were already in a chemically promoted state due to $\mathrm{O}^{2-}$ spillover during preparation. This phenomenon, caused by strong metal support interactions (SMSI), would result in the extension of the electric double layer over the gas-exposed catalyst surface, in analogy with emersed electrodes in liquid electrochemistry. Accordingly, smaller EPOC effect is expected with the $\mathbf{T d}$ catalysts than with the Sp catalyst.

The catalytic activity of the rhodium catalysts was studied towards the reaction between propylene and oxygen at $375{ }^{\circ} \mathrm{C}$. Under any experimental condition, no $\mathrm{CO}$ formation was detected and post-reaction XPS analysis did not show any significant carbon deposition. The only reaction occurring was the complete combustion of propylene:

$$
\mathrm{C}_{3} \mathrm{H}_{6}+\frac{9}{2} \mathrm{O}_{2} \rightarrow 3 \mathrm{CO}_{2}+3 \mathrm{H}_{2} \mathrm{O}
$$

The comparison of catalysts with respect to their catalytic activity is best done in terms of turnover 
frequency, TOF $\left(\mathrm{s}^{-1}\right)$, calculated as the ratio of the measured reaction rate, $\left.r(\mathrm{nmol} \mathrm{s})^{-1}\right)$ and the maximum propylene uptake, $N$ (nmol), determined by reactive surface titration. This latter measurement was performed with the catalysts only in their reduced form. In fact, the inverse titration of an oxidized catalyst is not possible, because both structural and adsorbed oxygen would react with propylene producing carbon dioxide, and they could not be distinguished.

The first series of catalytic measurements were made under open-circuit conditions. The reaction rate of $\mathrm{CO}_{2}$ production and the catalyst potential were measured at varying feed composition with a constant flow rate of $200 \mathrm{ml} \mathrm{min}^{-1}$ STP in the atmospheric reactor. The partial pressure of propylene was varied from zero to $500 \mathrm{~Pa}$, while the oxygen partial pressure was kept constant $(1000 \mathrm{~Pa})$. The results are shown in Figure 2, where the open-circuit reaction rate and catalyst potential are plotted as a function of the propylene partial pressure at the reactor outlet. The open-circuit reaction rate, $r_{\mathrm{o}}\left(\mathrm{nmolO} \mathrm{s}^{-1}\right)$, is given in terms of TOF $\left(\mathrm{s}^{-1}\right)$, while the catalyst potential, $V_{\mathrm{WR}}^{\mathrm{o}}(\mathrm{mV})$, is the opencircuit potential difference measured between the rhodium catalyst (working electrode) and the gold reference electrode.

The left part of Figure 2 shows the open-circuit TOF at varying gas composition, having a similar sigmoid shape for the three catalysts. All catalysts exhibited slow but increasing reaction rates at low propylene content, and much higher and fairly constant reaction rates at high propylene content. The transition from the first regime to the second, which appeared rather progressive with the Sp catalyst but quite abrupt with the samples $\mathbf{T d}_{500}$ and $\mathbf{T d} \mathbf{d}_{800}$, is dictated mainly by the change in the oxidation state of the catalysts, rhodium oxide being a poor catalyst and metallic rhodium being an efficient catalyst. The change occurred at gas compositions close to stoichiometric with respect to reaction Equation 1. It can be concluded that in oxidizing environment (low
$\mathrm{C}_{3} \mathrm{H}_{6}$ content) the $\mathbf{S p}$ catalyst was much less oxidized than the two Td samples which appeared almost identical, whereas in reducing environment (high $\mathrm{C}_{3} \mathrm{H}_{6}$ content) $\mathbf{S p}$ and $\mathbf{T} \mathbf{d}_{500}$ were similarly reduced while $\mathbf{T d}_{800}$ remained more oxidized. It is also seen that the Sp catalyst, being never completely oxidized, was more easily reduced, hence entered its high activity regime at lower $\mathrm{C}_{3} \mathrm{H}_{6}$ content, than the $\mathbf{T d}_{500}$ catalyst.

In the right part of Figure 2 the open-circuit catalyst potential, $V_{\mathrm{WR}}^{\mathrm{o}}$, is shown as a function of the propylene partial pressure. It was found that the jump in TOF, which was attributed to the reduction of the catalyst surface was accompanied by a drop in the catalyst potential. From thermodynamic point of view, the transformation between oxidized and reduced states is expected to occur at a given open-circuit catalyst potential, or equivalently, at a given surface activity of atomic oxygen, $a_{\mathrm{O}}$, at the three-phase boundary (tpb) of the catalyst (Equation 2):

$$
V_{\mathrm{WR}}^{\mathrm{o}}=\frac{R T}{4 F} \ln \left(\frac{a_{\mathrm{O}}^{2}}{P_{\mathrm{O}_{2}}}\right)
$$

where $P_{\mathrm{O}_{2}}$ is the partial pressure of oxygen at an ideal reference electrode. The underlying assumptions are that the electrodes are pure electron conductors while the solid electrolyte is a pure ion conductor, and that the only charge transfer reaction defining the potential is

$$
\mathrm{O}_{2}(\text { gas }) \rightleftharpoons 2 \mathrm{O}(\mathrm{tpb})+4 \mathrm{e}^{-}(\mathrm{cat}) \rightleftharpoons 2 \mathrm{O}^{2-}(\mathrm{YSZ})
$$

In this work a gold electrode was used as reference in a simplified one-chamber electrochemical cell, where the reference electrode was exposed to the reacting gas mixture of varying composition, so its potential was not constant. Nevertheless, comparison of the three catalysts by their potential measured in the plateau regions
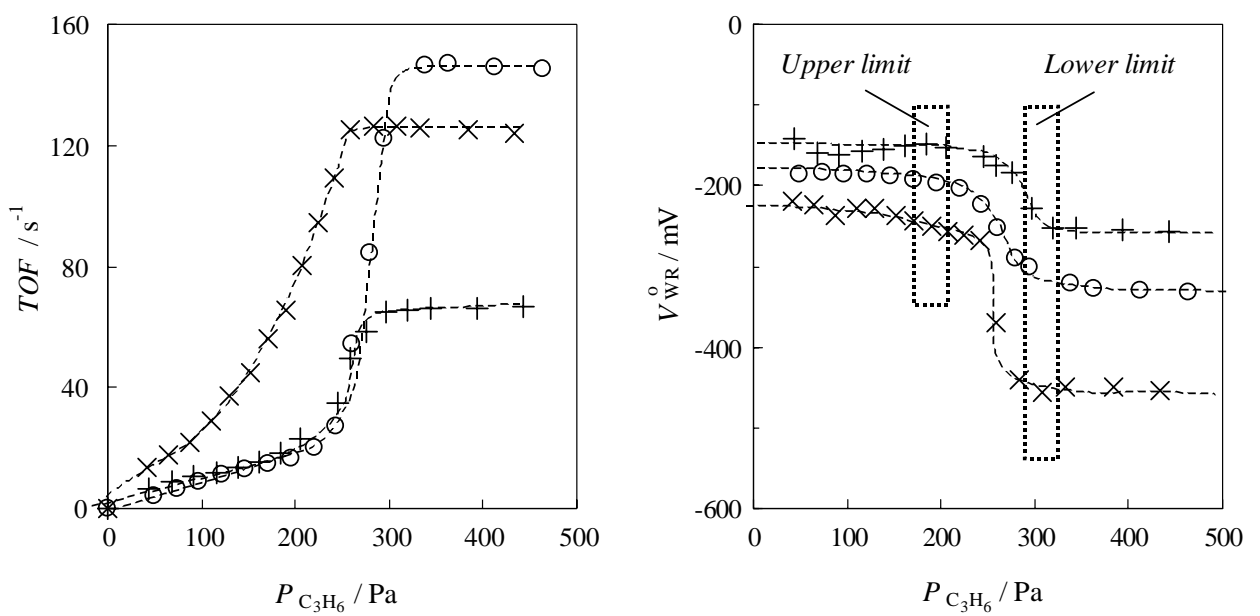

Fig. 2. Open-circuit combustion of propylene with oxygen on $\mathbf{S p}(\times), \mathbf{T d}_{500}(\bigcirc)$ and $\mathbf{T d}_{800}(+)$ rhodium/YSZ catalysts at $375{ }^{\circ} \mathrm{C}$ : turnover frequency, TOF (left), and catalyst potential, $V_{\mathrm{WR}}^{\mathrm{o}}$ (right), as a function of propylene partial pressure at the reactor outlet. Atmospheric operation; flow rate $200 \mathrm{ml} \mathrm{min}{ }^{-1} \mathrm{STP}$; inlet oxygen partial pressure $1000 \mathrm{~Pa}$. 
may be attempted due to the moderate conversion of the reactants $\left(\mathrm{C}_{3} \mathrm{H}_{6}\right.$ conversion up to 10,15 and $20 \%$ for the $\mathbf{T d}_{500}, \mathbf{T d}_{800}$ and Sp catalyst, respectively). It is seen that the $\mathbf{S p}$ catalyst was the most reduced while the $\mathbf{T d}_{800}$ catalyst was the most oxidized of the three samples at any gas composition, in good agreement with the instrumental surface analyses and with the observed catalytic activity.

Use of Equation 2 in order to calculate the activity of atomic oxygen at the three-phase boundary (tpb) of the catalyst needs the assumption that there is only one single charge transfer reaction (Equation 3) and it is in equilibrium at both electrodes. The gold reference electrode fairly well satisfied these assumptions, having a reasonably high exchange current and showing a steady-state current-potential behaviour independent of the presence of a hydrocarbon [41]. Assuming that the same ideal behaviour is valid also for the catalyst electrode, the oxygen activity at 'tpb' at a nominal oxygen partial pressure of $1 \mathrm{kPa}$ and at $375{ }^{\circ} \mathrm{C}$ is calculated as

$$
\begin{aligned}
\ln \left(a_{\mathrm{O}}^{2}\right) & =\frac{4 F}{R T}\left[V_{\mathrm{WR}}^{\mathrm{o}}+\frac{R T}{4 F} \ln \left(P_{\mathrm{O}_{2}}\right)\right] \\
& =0.072 \times\left[V_{\mathrm{WR}}^{\mathrm{o}}(\mathrm{mV})-64\right]
\end{aligned}
$$

Figure 3 shows the stability limits of bulk rhodium oxides, in terms of surface oxygen activity, $\ln \left(a_{\mathrm{O}}^{2}\right)$, at the temperature of measurements $\left(375^{\circ} \mathrm{C}\right)$ [43]. It is seen that $\mathrm{RhO}$ is not stable at this temperature. The Figure allows comparison of the bulk stability limits with the experimental $\ln \left(a_{\mathrm{O}}^{2}\right)$ values calculated with Equation 4 from the open-circuit potentials measured in the immediate proximity of the abrupt potential changes. These regions are also shown in Figure 2, labelled as 'Upper limit' for the surfaces just oxidized and as 'Lower limit' for the surfaces just reduced. The oxygen activity of the oxidized Sp catalyst fell in the partially oxidized region between stable $\mathrm{Rh}$ and $\mathrm{Rh}_{2} \mathrm{O}_{3}$, and it was shifted deeply into the $\mathrm{Rh}$ region after reduction. The $\mathbf{T} \mathbf{d}_{500}$ catalyst was more oxidized in its oxidized state, but it also became completely reduced. The $\mathbf{T d}_{800}$ catalyst, although situated just at the limit of $\mathrm{Rh}_{2} \mathrm{O}_{3}$ stability when oxidized, did not exhibit a shift big enough to enter the metallic $\mathrm{Rh}$ region, so it remained partially oxidized after reduction.

The qualitative agreement between the surface oxidation state estimated from potential measurements and the observed catalytic activity is satisfactory, taking into account that $a_{\mathrm{O}}$ is a property of the 'tpb' while the reaction rate reflects the average of the whole gasexposed surface. In non-equilibrium conditions, significant concentration gradients may be present at the catalyst surface resulting in an underestimation of the average oxygen activity. Another limitation of the use of solid electrolyte potentiometry in reacting environment is the possible contribution of a reaction other than Equation 3 to the charge transfer at the catalyst electrode resulting in a mixed potential. This effect is rather probable in rich hydrocarbon conditions. Such observations were reported also with a rhodium catalyst prepared by thermal decomposition of a commercial organo-rhodium paste employed for the combustion of ethylene in the temperature range of 300 to $400{ }^{\circ} \mathrm{C}$ [34]. In that work, oxygen activity values at the oxidized rhodium surface were obtained systematically well below the stability limit of bulk metallic rhodium. Despite these limitations, and even when measured in a one-chamber cell where the reference electrode is not separated from the reacting gas of varying composition, the open-circuit catalyst potential appeared a sensitive in situ indicator of the average oxidation state, hence also

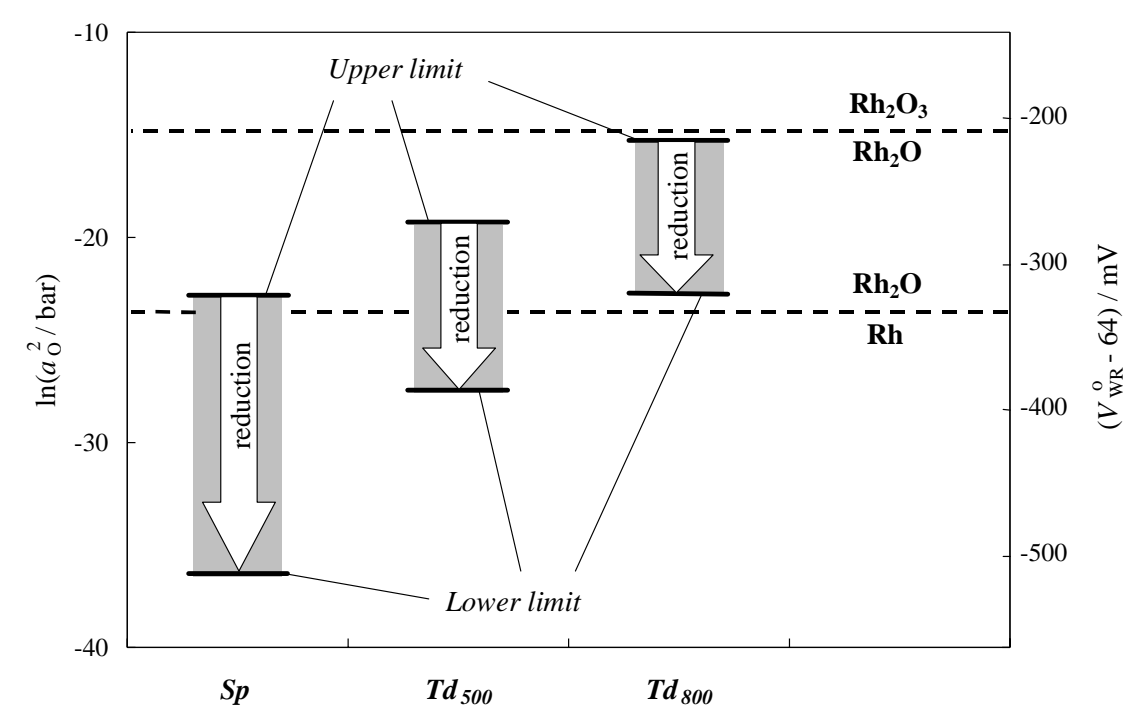

Fig. 3. Activity of atomic oxygen, $a_{\mathrm{O}}$, at the 'tpb' of the Sp, $\mathbf{T d}_{500}$ and $\mathbf{T} \mathbf{d}_{800}$ rhodium/YSZ catalysts at the 'Upper limit' and the 'Lower limit' of the potential change shown in Figure 2, in comparison with the stability limits of bulk rhodium oxides in terms of $\ln \left(a_{\mathrm{O}}^{2}\right)$ at measurement temperature $\left(375^{\circ} \mathrm{C}\right)$. Right vertical axis shows corresponding corrected (Equation 4) open-circuit potentials. Arrows indicate direction of shift during surface reduction. 
that of the catalytic activity, of rhodium catalysts deposited on YSZ solid electrolyte support.

In a closed-circuit operation, the catalyst potential is a convenient tool to tune the activity of the catalyst. Application of a potential may cause a nonfaradaic enhancement of the catalytic reaction rate. The electrochemical promotion of catalysis (EPOC) is usually quantified by the rate enhancement factor, $\rho$, defined with Equation 5:

$$
\rho=\frac{r}{r_{\mathrm{o}}}
$$

where $r_{\mathrm{o}}$ and $r\left(\mathrm{nmolO} \mathrm{s}{ }^{-1}\right)$ are the open-circuit and the electrochemically promoted reaction rate, respectively, and by the faradaic enhancement factor, $\Lambda$, defined with Equation 6:

$$
\Lambda=\left(r-r_{\mathrm{o}}\right) \times \frac{z F}{I}
$$

where $I(\mu \mathrm{A})$ is the applied current, $z$ is the charge number of transported ions (for $\mathrm{O}^{2-}, z=2$ ), and $F$ $\left(=96.5 \mu \mathrm{C} \mathrm{nmol}^{-1}\right)$ is the faradaic constant.

The EPOC experiments were carried out at $375{ }^{\circ} \mathrm{C}$ in galvanostatic polarization mode with varying applied anodic current up to $100 \mu \mathrm{A}$. For all three catalysts, the largest promotion was obtained with gas compositions close to stoichiometric, exemplified in Figure 4. In these experiments, the inlet partial pressures were $1000 \mathrm{~Pa}$ of $\mathrm{O}_{2}$ and $225 \mathrm{~Pa}$ of $\mathrm{C}_{3} \mathrm{H}_{6}$. At this composition and under open-circuit conditions all three catalysts were found in their oxidized form but close to the limit of surface reduction (labelled as 'Upper limit' in Figure 2). The left part of Figure 4 shows the steady-state rate enhancement factor, $\rho$, as a function of the ohmic-drop-free catalyst potential, $V_{\text {WR }}$. The $\mathbf{S p}$ catalyst showed the strongest promotion (up to $\rho=2$ ), while the $\mathbf{T} \mathbf{d}_{800}$ catalyst was the less sensitive to EPOC $(\rho<1.2)$. The right part of Figure 4 shows the steady-state faradaic efficiency, $\Lambda$, as a function of the applied current, $I$. It is seen that the effect of EPOC was highly nonfaradaic in all cases resulting in $\Lambda$ values, extrapolated to zero current [41], of about 900, 250 and 100 for the $\mathbf{S p}, \mathbf{T d}_{500}$ and $\mathbf{T} \mathbf{d}_{800}$ catalyst, respectively. The origin of this high promotion was the anodic polarization of the catalyst/ YSZ interface, which generated $\mathrm{O}^{2-}$ spillover species at the 'tpb'. Spreading out of these species over the gasexposed, hence catalytically active, surface decreased the rhodium-oxygen binding energy, thus it assisted also to the decomposition of surface rhodium oxide at a gas composition where, under open-circuit conditions, the rhodium oxide surface sites appeared stable. EPOC was found the most efficient with the Sp catalyst although it remained partially reduced even after oxidation (Table 1). This is in good qualitative agreement with the results of XPS analysis (Table 2), which indicated that the Td catalysts, and especially that prepared at $800{ }^{\circ} \mathrm{C}$, were in a chemically promoted state already under opencircuit conditions due to oxygen spillover during preparation, which made them less sensitive to EPOC in comparison with the $\mathbf{S p}$ catalyst.

\section{Conclusions}

Rhodium catalysts were deposited on YSZ solid electrolyte support by two techniques: rhodium plasma sputtering (Sp), and thermal decomposition of $\mathrm{RhCl}_{3}$ precursor at $500{ }^{\circ} \mathrm{C}\left(\mathbf{T d}_{500}\right)$ and at $800{ }^{\circ} \mathrm{C}\left(\mathbf{T d}_{800}\right)$. XPS and XRD measurements evidenced that, as prepared, the Sp catalyst film was crystalline metallic rhodium, the $\mathbf{T d}_{500}$ catalyst was amorphous and only partially decomposed, and the $\mathbf{T} \mathbf{d}_{800}$ catalyst was mainly composed of crystalline $\mathrm{Rh}_{2} \mathrm{O}_{3}$. Oxidizing or reducing treatment at $375^{\circ} \mathrm{C}$ was shown to modify only the outer surface of the catalysts. The $\mathbf{S p}$ catalyst remained partially reduced after oxidation, the $\mathbf{T} \mathbf{d}_{800}$ catalyst remained partially oxidized after reduction, and the $\mathbf{T d}_{500}$ catalyst exhibited
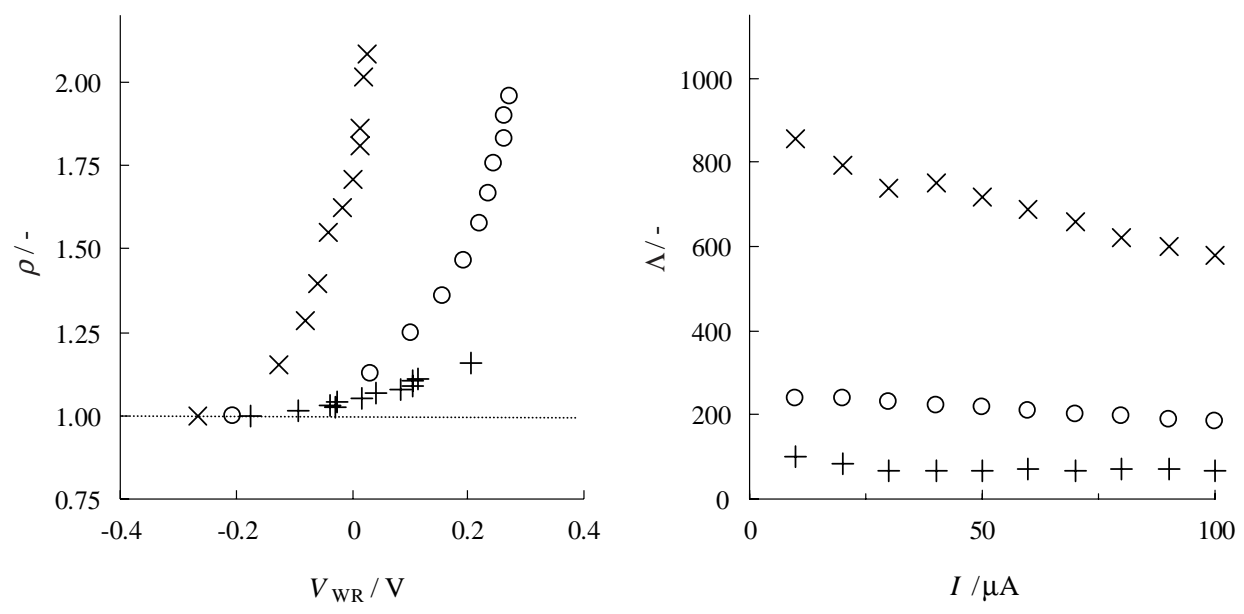

Fig. 4. Electrochemical promotion of the $\mathbf{S p}(\times), \mathbf{T d}_{500}(\odot)$ and $\mathbf{T} \mathbf{d}_{800}(+)$ rhodium/YSZ catalysts in the combustion reaction of propylene. Left: steady-state rate enhancement factor, $\rho$, as a function of the ohmic-drop-free catalyst potential, $V_{\mathrm{WR}}$. Right: steady-state faradaic efficiency, $\Lambda$, as a function of the applied current, $I$. Feed composition: $\mathrm{O}_{2}(1000 \mathrm{~Pa})$ and $\mathrm{C}_{3} \mathrm{H}_{6}(225 \mathrm{~Pa}) ; T=375^{\circ} \mathrm{C}$. 
an intermediate behaviour. $\mathrm{O} / \mathrm{Rh}$ atomic ratios higher than stoichiometric were found by XPS at the outer surface of the catalysts suggesting $\mathrm{O}^{2-}$ spillover due to strong metal support interactions. The effect was particularly pronounced with the Td catalysts. The rhodium films served both as working electrode in the electrochemical cell and as catalyst for the reaction of propylene combustion at $375^{\circ} \mathrm{C}$. Under open-circuit conditions, the catalytic reaction rate appeared to depend strongly on the oxidation state of the catalyst, a reduced catalyst being much more active than an oxidized catalyst. The change in the catalyst oxidation state due to varying composition of the reacting gas mixture was accompanied by a shift of several hundred millivolts in the open-circuit catalyst potential. Following the principle of solid electrolyte potentiometry, the activity of oxygen at the 'tpb' during the open-circuit catalytic reaction was estimated close to the limits of the change in surface oxidation state. Oxygen activities were found in good agreement with the average surface oxidation state suggested by XRD and XPS analyses. While the open-circuit catalyst potential appeared a suitable indicator of the oxidation state of the catalyst surface, under closed-circuit conditions the potential of the catalyst was a convenient tool to tune in situ the catalytic activity. At stochiometric gas composition, where in open-circuit conditions the rhodium catalysts were just oxidized but close to the limit of surface reduction, electrochemical promotion was highly nonfaradaic, indicating that the catalyst surface became partially reduced under positive potential application. This was due to electrogenerated $\mathrm{O}^{2-}$ spillover toward the gas-exposed catalyst surface, which is known to weaken the rhodium-oxygen bonding strength. Catalysts exhibiting higher $\mathrm{O}^{2-}$ spillover during preparation, thus being promoted to some extent already in opencircuit conditions, are expected to be less efficient in electrochemical promotion. Accordingly, the efficiency of EPOC decreased in the order $\mathbf{S p}>\mathbf{T d}_{500}>$ $\mathbf{T d}_{800}$.

\section{Acknowledgements}

Financial supports from the Fonds National Suisse de la Recherche Scientifique and from the Office Fédéral Suisse de l'Éducation et de la Science are gratefully acknowledged. The authors are grateful to Professor Francis Lévy, Swiss Federal Institute of Technology, Lausanne, for the sputter deposition of rhodium.

\section{References}

1. N.W. Cant and W.K. Hall, J. Catal. 16 (1970) 220.

2. S.H. Oh and J.E. Carpenter, J. Catal. 80 (1983) 472.

3. G.L. Kellogg, Surf. Sci. 171 (1986) 359.

4. D.G. Castner, B.A. Sexton and G.A. Somorjai, Surf. Sci. 71 (1978) 519.
5. H.C. Yao, S. Japar and M. Shelef, J. Catal. 50 (1977) 407.

6. C. Wagner, Adv. Catal. 21 (1970) 323.

7. C.G. Vayenas, B. Lee and J. Michaels, J. Catal. 66 (1980) 36.

8. I.V. Yentekakis, S. Neophytides and C.G. Vayenas, J. Catal. 111 (1988) 152.

9. C.G. Vayenas, S. Bebelis and S. Neophytides, J. Phys. Chem. 92 (1988) 5083.

10. C.G. Vayenas, S. Bebelis, C. Pliangos, S. Brosda and D. Tsiplakides, 'Electrochemical Activation of Catalysis' (Kluwer Academic/Plenum, New York, 2001).

11. G. Fóti, I. Bolzonella and Ch. Comninellis, 'Electrochemical promotion of catalysis' in B.E. Conway, C.G. Vayenas and R.E. White (Eds) 'Modern Aspects of Electrochemistry' (Kluwer/ Plenum, New York, 2003), 36.

12. G. Fóti, S. Wodiunig and Ch. Comninellis, Curr. Top. Electrochem. 7 (2000) 1.

13. J.O'M. Bockris, A.K.N. Reddy and M. Gamboa-Aldecco, in 'Modern Electrochemistry' (Kluwer Academic/Plenum, New York, 2000).

14. K. Juttner, U. Galla and H. Schmieder, Electrochim. Acta 45 (2000) 2575.

15. G. Ertl, H. Knötzinger and J. Weitkamp, 'Handbook of Catalysis' (VCH, Weinheim, 1997).

16. J. Pritchard, Nature 343 (1990) 592.

17. G.-Q. Lu and A. Wieckowski, Curr. Opin. Colloid Interface Sci. 5 (2000) 95.

18. E. Varkaraki, J. Nicole, E. Plattner, Ch. Comninellis and C.G. Vayenas, J. Appl. Electrochem. 25 (1995) 978.

19. J. Nicole, D.T. Tsiplakides, S. Wodiunig and Ch. Comninellis, J. Electrochem. Soc. 144 (1997) L312.

20. J. Nicole and Ch. Comninellis, Solid State Ionics 136-137 (2000) 687.

21. S. Wodiunig 'Electrochemical Promotion of Ruthenium Oxide Catalysts for the Gas Phase Combustion of Ethylene', Thesis 2138, EPFL, Lausanne (2000).

22. S. Wodiunig, F. Bokeloh, J. Nicole and Ch. Comninellis, Electrochem. Solid-State Lett. 2 (1999) 281.

23. S. Wodiunig and Ch. Comninellis, J. Eur. Ceram. Soc. 19 (1999) 931 .

24. S. Wodiunig, Ch. Comninellis and C. Mousty, in E.J. Rudd and C.W. Walton (Eds), 'Energy and Electrochemical Processing for a Cleaner Environment', The Electrochemical Society Proceedings Series, Pennington, NJ, 147 (1997).

25. S. Wodiunig, V. Patsis and Ch. Comninellis, Solid State Ionics 136-137 (2000) 813.

26. Z.L. Zhang, V.A. Tsipouriari, A.M. Efstathiou and X.E. Verykios, J. Catal. 158 (1996) 51.

27. S.C. Chuang, R. Krishnamurthy and C-D. Tan, Colloids Surf. A 105 (1995) 35.

28. G.R. Bamwenda, A. Obuchi, A. Ogata, J. Oi, S. Kushiyama and K. Mizuno, React. Kinet. Catal. Lett. 63 (1998) 53.

29. P. Mériaudeau, O.H. Ellestad, M. Dufaux and C. Naccache, J. Catal. 75 (1982) 243.

30. F. Solymosi, I. Tombácz and M. Kocsis, J. Catal. 75 (1982) 78.

31. E.A. Efthimiadis, S.C. Christoforou, A.A. Nikolopoulos and I.A. Vasalos, Appl. Catal. B 22 (1999) 91.

32. R. Burch, P.K.Loader and N.A. Cruise, Appl. Catal. A 147 (1996) 375 .

33. K. Rahkamaa and T. Salmi, Chem. Eng. Sci. 54 (1999) 4343.

34. C. Pliangos, I.V. Yentekakis, X.E. Verykios and C.G. Vayenas, J. Catal. 154 (1995) 124.

35. R.V. Stuart, 'Vacuum Technology, Thin Films and Sputtering: an Introduction' (Academic Press, New York, 1983).

36. A. Kaloyannis, C. Pliangos, I.V. Yentekakis and C.G. Vayenas, Ionics 1 (1995) 159

37. C. Pliangos, I.V. Yentekakis, V.G. Papadakis, C.G. Vayenas and X.E. Verykios, Appl. Catal. B 14 (1997) 161.

38. G. Fóti, O. Lavanchy and Ch. Comninellis, J. Appl. Electrochem. 30 (2000) 1223 
39. J. Nicole, D. Tsiplakides, C. Pliangos, X.E. Verykios, Ch Comninellis and C.G. Vayenas, J. Catal. 204 (2001) 23.

40. S.B. Adler, J. Electrochem. Soc. 149 (2002) E166.

41. G. Fóti, V. Stankovic, I. Bolzonella and Ch. Comninellis, J. Electroanal. Chem. 532 (2002) 191.
42. J. Nicole, 'Etude de la Promotion Électrochimique de l'Oxydation Catalytique de l'Éthylène sur des Oxydes Métalliques', Thesis 1933, EPFL, Lausanne (1999).

43. L. Riekert, Ber. Bunsenges. Phys. Chem. 85 (1981) 297. 